\title{
Les peptides de la défense antimicrobienne des vertébrés
}

A côté de leur système immun, responsable de mécanismes spécifiques de défense contre les agents infectieux, les vertébrés possèdent de nombreux peptides à action antimicrobienne. Ces peptides sont seuls présents chez les invertébrés à courte durée de vie et à taux de renouvellement élevé, chez lesquels un système immunitaire, à mémoire, long à s'établir et à développer une réponse appropriée, serait inadapté. Les peptides antimicrobiens peuvent être classés en trois grandes familles selon leurs caractéristiques structurales principales : hélices $\alpha$-amphipathiques, feuillets $\beta$ réunis par des ponts disulfure ou chaîne destructurée aux nombreux coudes provoqués par la richesse en proline. Toutes ces molécules sont fortement cationiques et peuvent interagir, par des résidus hydrophobes, avec la bicouche lipidique des membranes dans lesquelles elles formeraient des canaux ioniques dépendant du voltage et peu spécifiques. Ce sont les canaux ainsi formés qui seraient responsables de la dissipation de la polarité membranaire et, par conséquent, de la lyse cellulaire.

\section{Pierre Nicolas Amram Mor Antoine Delfour}

\section{ADRESSE}

P. Nicolas : professeur à l'université Paris-VI. A. Mor : chercheur associé au Cnrs. A. Delfour : professeur à l'université de Poitiers. Laboratoire de bioactivation des peptides, institut Jacques-Monod, université Paris-VII, 2, place Jussieu, 75251 Paris Cedex 05, France.

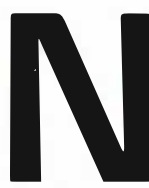

otre environnement foisonne de micro-organismes tels que bactéries, champignons, virus et autres parasites. La dissémination et la prolifération de ces germes dans un organisme hôte peuvent donner lieu, si elles ne sont pas convenablement jugulées, à des infections occasionnelles susceptibles de mettre en jeu le pronostic vital. Un grand nombre de ces microorganismes vivent également comme commensaux ou saprophytes dans les cavités internes de la plupart des organismes vivants. Bien que ces commensaux soient utiles à l'organisme qui les héberge puisque, entre autres, ils interdisent l'accès de leurs niches écologiques aux germes pathogènes, leur développement incontrôlé peut aboutir à des infections oppor- tunistes et à des désordres pathologiques sévères. Tous les êtres vivants, du plus simple au plus complexe, ont donc élaboré des systèmes de défense adaptés pour combattre et détruire tout agent pathogène, qu'il soit occasionnel ou obligatoire, et pour confiner les micro-organismes de leur flore naturelle à leurs sites commensaux. Les systèmes de défense antimicrobienne des différents phylums de vertébrés et d'invertébrés révèlent d'importantes différences structurales et fonctionnelles. Les mammifêres et les chordés en général sont dotés d'un système immunitaire complexe, à médiation humorale et cellulaire, où l'immunité naturelle non spécifique se double d'une immunité spécifique, dite à mémoire. Alors que l'activation de cette dernière requiert des signaux multiples et une cascade complexe 
d'événements, elle assure à l'organisme une protection très spécifique et de longue durée contre les germes pathogènes occasionnels. Bien que des tissus lymphoïdes primitifs soient présents chez les invertébrés, la part de l'immunité à mémoire y semble faible, voire inexistante, et aucune molécule apparentée aux immunoglobulines n'a pu y être détectée. Les invertébrés combattent très efficacement la prolifération des microorganismes de leur flore naturelle en synthétisant et en libérant, lors d'infections occasionnelles, un répertoire fixe de peptides antimicrobiens à spectre d'action étendu.

L'absence d'une immunité cellulaire fonctionnelle à mémoire chez les

\section{RÉFÉRENCES}

1. Segrest JP, De Loof $H$, Dohlman JG, Brouillette CG, Anantharamaiah GM . Amphiphatic helix motif: classes and properties. Proteins $1990 ; 8: 103-17$

2. Boman HG, Haltmark D. Cell free immunity in insects. Ann Rev Microbiol $1987 ; 41: 103-26$.

3. Lee JY, Boman A, Sun C, et al. Antibacterial peptides from pig intestine : isolation of a mammalian cecropin. Proc Natl Acad Sci USA 1989 ; 86 : 9159-62.

4. Erspamer V. Half a century of comparative research on biogenic amines and active peptides in amphibian skin and molluscan tissues. Comp Biochem Physiol 1984 ; 79: 1-7.

5. Gibson BW. Lytic peptides from skin secretions of Xenopus laevis : a personal perspective. In : Gibson B, ed. Surface Reactive Peptides and Polymers. American Chemical Society, 1991 ; 222-35.

6. Zasloff M. Magainins, a class of antimicrobial peptides from Xenopus skin. Isolation, characterization of 2 active forms and partial cDNA sequence of a precursor. Proc Natl Acad Sci USA 1987 ; 84 : 5449-53.

7. Zasloff M, Martin B, Chen HC. Antimicrobial activity of synthetic magainin peptides and several analogs. Proc Natl Acad Sci USA 1988 ; 85 : 910-3.

8. Simmaco M, Barra D, Chiarni F, et al. A family of bombinin-related peptides from the skin of Bombina varietaga. Eur $J$ Biochem invertébrés peut se comprendre en regard de leur courte vie et de leur taux de reproduction élevé. De tels organismes peuvent se permettre de perdre $90 \%$ de leur population lors d'une infection par un germe pathogène contre lequel les peptides antimicrobiens de leur système de défense chimique sont peu efficaces. Les individus survivants, en se multipliant rapidement, rétabliront l'effectif initial de la population. Pour ces organismes, un système immunitaire à mémoire est mal adapté et d'un coût trop élevé puisque leur multiplication rapide peut, à elle seule, garantir la survie de l'espèce face à des agents infectieux inconnus. En contraste avec l'immense majorité des invertébrés, les vertébrés sont des organismes qui combinent une vie longue et un faible taux de reproduction. Face aux infections, ils ne peuvent se permettre de sacrifier une part importante de leurs effectifs au risque de disparaître. Avec l'immunité à mémoire, ces animaux bénéficient d'une protection particulièrement bien adaptée contre les pathogènes occasionnels puisque celle-ci leur permet une destruction spécifique de ces germes et une protection ultérieure en cas de réinfection. Ces différences dans l'organisation et les modes d'action des systèmes de défense qui sont mis en œuvre chez les invertébrés et les vertébrés pour endiguer la prolifération des micro-organismes refléteraient pour partie la croissance régulière de la complexité des organismes vivants et de leurs systèmes immunitaires au cours de l'évolution, mais aussi l'adaptation particulière de ces systèmes immunitaires aux divers modes de vie des organismes vivants. Pour les organismes simples et à croissance rapide, un système de déf ense chimique principalement destiné au contrôle des flores naturelles et commensales ; système à induction rapide mais peu spécifique, à spectre d'action étendu mais fixe et qui ne nécessite pas de lignée cellulaire ou de tissus particuliers. Pour les organismes plus complexes, à croissance lente, une défense à mémoire et à support cellulaire dont l'induction est plus lente mais qui procure une couverture spécifique et de longue durée contre les germes pathogènes, occasionnels ou obligatoires.
La découverte répétée, au cours de ces dernières années, de peptides antimicrobiens chez les vertébrés a révélé l'existence, jusque chez les mammifères, d'un système inductible de défense chimique contre les microorganismes qui coexiste avec le système immunitaire classique. L'analyse des composants et des modes d'action de ce système de lutte chimique a amélioré notre compréhension des moyens mis en œuvre par les vertébrés pour survivre dans un monde infesté de microorganismes et ouvre de nouvelles perspectives dans la thérapeutique des infections opportunistes

Plus d'une cinquantaine de peptides antimicrobiens de vertébrés ont été isolés et caractérisés à ce jour. Quelle qu'en soit l'origine - vertébrés inférieurs ou supérieurs, tissus myéloïdes ou non myéloïdes - , ces peptides ont en commun une petite taille, un caractère cationique et une action membranolytique. Au contraire des peptides antibiotiques des microorganismes qui, pour la plupart, sont synthétisés par la voie enzymatique, les peptides de défense des vertébrés sont synthétisés classiquement par la voie ribosomique via des précurseurs biosynthétiques de grande taille. Aucune des modifications posttraductionnelles de chaînes latérales des acides aminés répertoriés dans les neuropeptides et les hormones n'est présente dans les peptides antimicrobiens des vertébrés. Malgré une extrême hétérogénéité de structure primaire et l'absence de séquence consensus, les peptides antimicrobiens des vertébrés sont regroupés en trois familles distinctes sur la base de leur structure secondotertiaires : les peptides en hélice $\alpha$ amphiphile, les peptides à ponts disulfures et en feuillet $\beta$, et les peptides riches en proline.

\section{Les peptides antimicrobiens formant des hélices $\alpha$-amphipatiques}

Bien que ne présentant pas ou peu d'homologie de structure primaire, de nombreux peptides antimicrobiens de vertébrés et d'invertébrés montrent une forte tendance à se structurer en hélice $\alpha$-amphiphile en présence de $\mathrm{m} / \mathrm{s} n^{\circ} 5$, vol. 8, mai 92 
solvants apolaires qui miment l'environnement membranaire lipidique. Une des faces de l'hélice renferme la majorité des acides aminés polaires ou chargés alors que les acides aminés hydrophobes sont situés sur la face opposée. Cette amphiphilicité de la structure semble conférer à ces peptides leurs communes propriétés d'interagir avec les bicouches lipidiques, d'en perturber l'organisation et d'induire ainsi la lyse cellulaire. L'hélice $\alpha$-amphiphile est un motif structural très usuel puisqu'il est présent dans les apolipoprotéines, les hormones polypeptidiques, les protéines globulaires, les protéines liant le calcium et dans les domaines transmembranaires des protéines de membrane [1]. Dans les peptides antimicrobiens, ce motif structural possède des caractéristiques particulières (figure 1). L'hydrophobicité de ces peptides est en effet particulièrement élevée et la face apolaire de l'hélice couvre une surface plus importante que celle de la face polaire. Cette dernière est fortement chargée, la lysine prédomine au détriment de l'arginine.

Les cécropines [2], peptides antibactériens initialement isolés chez certains insectes puis découverts par la suite chez les mammifères, sont les représentants primitifs de cette famille structurale. La cécropine de la muqueuse intestinale du porc [3] et les cécropines d'insecte sont des peptides cationiques de 31 à 39 acides aminés, riches en lysine (Tableau I, p. 426). Ces peptides sont synthétisés via des précurseurs biosynthétiques de 62 à 64 acides aminés. L'organisation de ces précurseurs est classique ; ils comprennent un peptide signal hydrophobe $\mathrm{N}$-terminal qui précède une séquence progénitrice du peptide actif, bordée en amont et en aval de doublets d'acides aminés basiques qui servent de sites de coupure pour des endoprotéases de maturation. Les séquences primaires des cécropines sont fortement homologues; elles sont constituées d'une alternance de motifs riches en acides aminés polaires et non polaires. En présence de lipides ou de solvants apolaires, les cécropines adoptent une structure composée de deux hélices $\alpha$ liées par un segment 12-24 très flexible. Alors que l'hélice $\mathrm{N}$-terminale est fortement amphipatique, l'hélice C-terminale est $\mathrm{m} / \mathrm{s} n^{\circ} 5$, vol. 8, mai 92

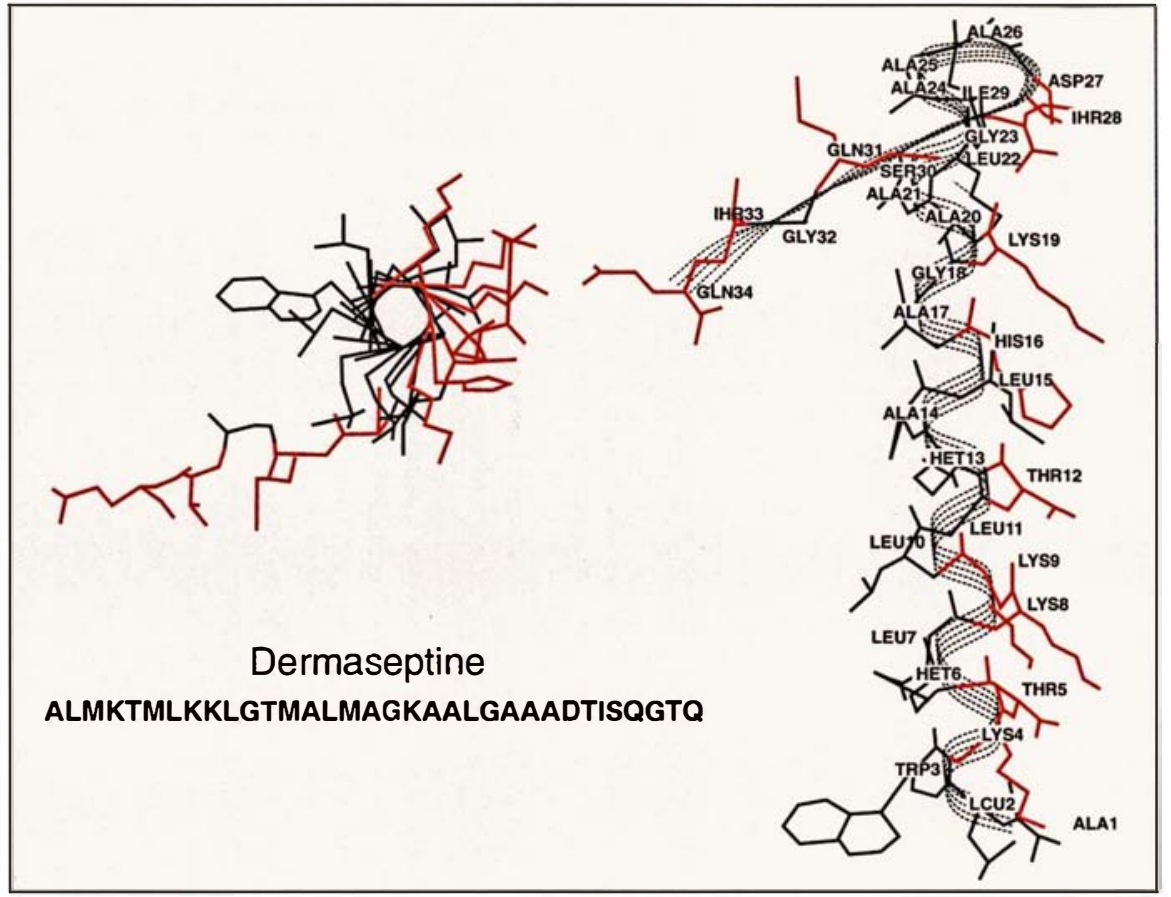

Figure 1. La dermaseptine, un peptide antimicrobien de 34 acides aminés isolé de la peau de la rainette sud-américaine Phyllomedusa sauvagii, détruit certains champignons mycéliens pathogènes chez I'homme, comme l'Aspergillus, en désorganisant la structure de la membrane de ces organismes. Dans un milieu apolaire qui mime l'environnement membranaire, les 27 premiers acides aminés de la dermaseptine forment une hélice $\alpha$-amphipatique là gauche, une vue transversale de l'extrémité $N$-terminale vers l'extrémité C-terminale de I'hélice; à droite, une vue longitudinale de I'hélice) dans laquelle les résidus polaires (en rouge) et les résidus apolaires (en noir) se répartissent sur des faces opposées de l'hélice.

plutôt hydrophobe. Les cécropines sont bactéricides contre une grande variété de bactéries Gram ${ }^{+}$et Gram -. L'action bactéricide de la cécropine semble liée à sa capacité de s'insérer dans les bicouches lipidiques et d'y former des canaux ioniques dépendants du voltage à faible sélectivité anionique [2]. Ces canaux induisent une perturbation des équilibres ioniques et une dissipation du potentiel transmembranaire qui aboutissent à la lyse cellulaire. Malgré leur grande toxicité vis-à-vis des membranes bactériennes, les cécropines sont dépourvues d'action sur les cellules eucaryotes. La spécificité des cécropines pour les membranes procaryotes provient vraisemblablement des compositions lipidiques différentes des membranes eucaryotes et procaryotes. En particulier, l'insertion de cholestérol dans la membrane rend les liposomes résistants à la lyse par les cécropines.

La peau des amphibiens est une riche source de peptides antimicrobiens de structure et de spécificité d'action très variées. Les glandes dermiques des amphibiens synthétisent et sécrètent en effet des quantités extraordinaires de peptides biologiquement actifs dont on trouve la contrepartie, sous la forme de peptides de structure identique ou voisine, dans le système nerveux central et le tractus gastrointestinal des mammifères [4]. La peau des amphibiens sert donc de modèle pour isoler et caractériser de nouvelles hormones ou des peptides antimicrobiens présents à l'état de traces chez les mammifères et pour étudier le mécanisme d'action et les voies de biosynthèse de ces peptides. Les peptides antimicrobiens isolés de la peau du xénope sont regroupés en deux familles selon qu'ils proviennent de précurseurs biosynthétiques pluriou monofonctionnels. Le fragment de la proxénopsine, ou XPF, et les fragments de la procaeruléine (ou CPF) sont issus de la maturation posttraductionnelle de précurseurs hormonaux plurifonctionnels des amphi- 
Tableau 1

SÉQUENCE EN ACIDES AMINÉS DES PRINCIPAUX PEPTIDES ANTIMICROBIENS DE VERTÉBRÉS ET D'INVERTÉBRÉS. LES SÉQUENCES SONT ALIGNÉES DE FAÇON A OPTIMALISER LES HOMOLOGIES

\begin{tabular}{|c|c|}
\hline & Peptides en hélice amphipatique \\
\hline $\begin{array}{l}\text { Cécropines } \\
\text { Insectes } \\
\text { Hyalophora } \\
\text { Bombyx } \\
\text { Sarcophaga } \\
\text { Manduca } \\
\text { Porc } \\
\text { Bombinines }\end{array}$ & 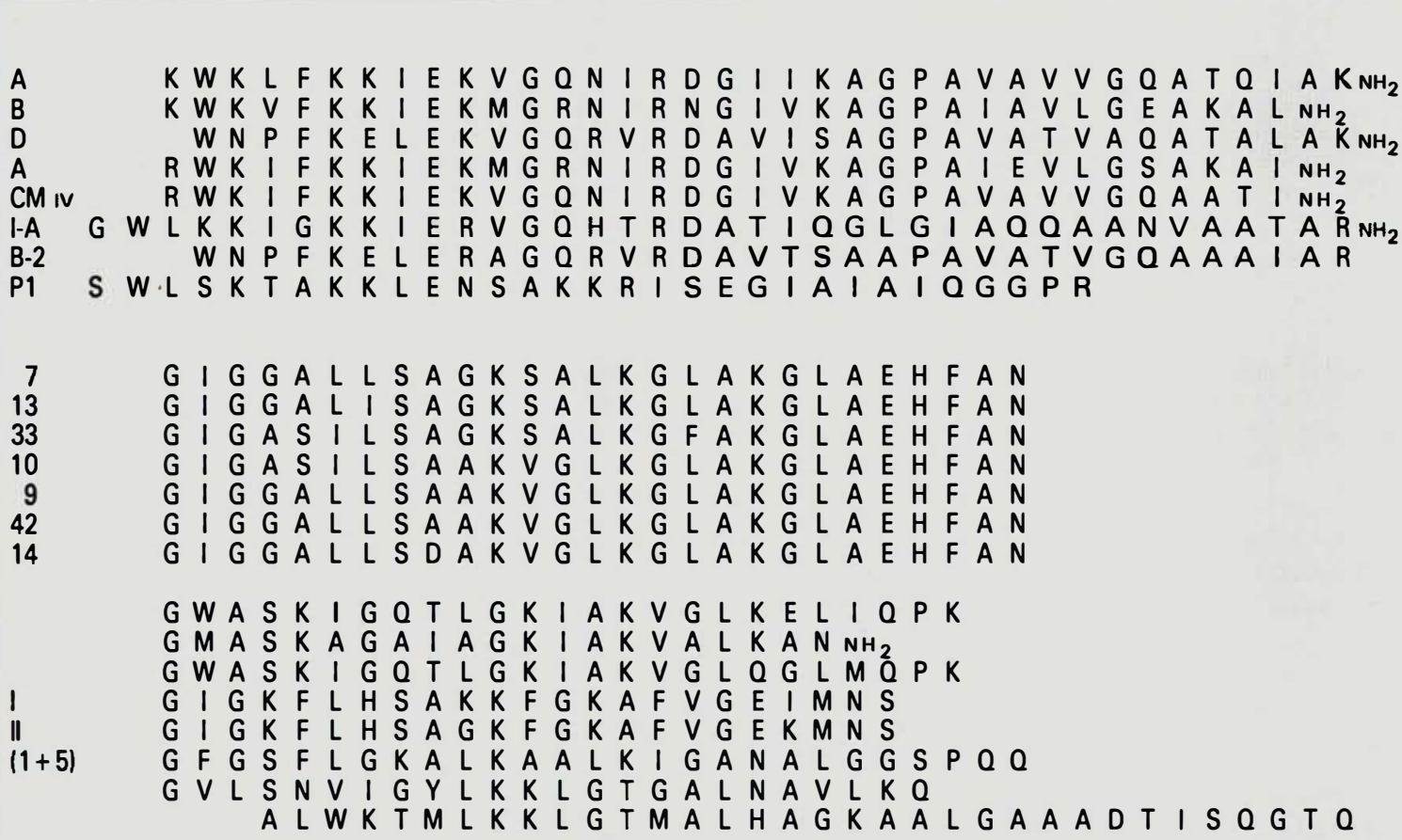 \\
\hline $\begin{array}{l}\text { XPF } \\
\text { PGLa } \\
\text { PGK } \\
\text { Magainines } \\
\text { CPF } \\
\text { PGQ } \\
\text { Dermaseptine }\end{array}$ & Peptides à feuillets $\beta$ \\
\hline $\begin{array}{l}\text { Défensine } \\
\text { Homme } \\
\text { Cobaye } \\
\text { Lapin } \\
\text { Rat }\end{array}$ & 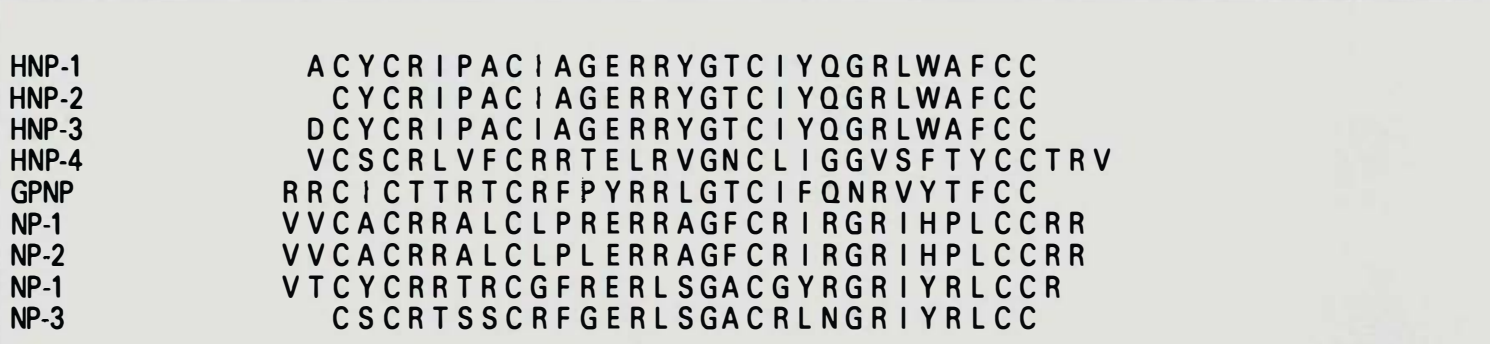 \\
\hline \multicolumn{2}{|c|}{$\begin{array}{l}\text { Cryptidine } \\
\text { TAP NCYCRSRGCKGRERMNGTCRKGHL I Y TLCCR } \\
\text { NPVSCVRNKG I CVP IRCPGSMKOIGTCVGRAVKCCRKK }\end{array}$} \\
\hline \multirow[t]{2}{*}{$\begin{array}{l}\text { Sapécine } \\
\text { Phormicine } \\
\text { Royalisine } \\
\text { Thionine } \\
\text { (BTH6) }\end{array}$} & $\begin{array}{l}\text { ATCDLLSGTGINHSACAAHCLLRGNRGGYCNGKAVCVCRN } \\
\text { ATCDLLSGTGINHDACAAHCLLRGNRGGYCNGKAVCVCRN } \\
\text { VTCDLLSFKGOVNDSACAANCLSLGKAGGICEKGVCICRKTSFKDLWDKYF } \\
\text { KSCCKDTLARNCYNTCRFAGGSRPVCAGACRCKIISPGKCPSDYPK }\end{array}$ \\
\hline & Peptides riches en prolines \\
\hline Bacténécines & $\begin{array}{l}\text { Bac } 5 \text { RF RPP IRRPP IRPPFYPPFRPP IRPP IFPP IRPPFRPPLRFP } \\
\text { Bac } 7 \text { R I R R R P R PRPRPRPLPFPRPGPRP I PRPLPFPRPGPRPIPRPLPFPRPGB } \\
\text { PR P }\end{array}$ \\
\hline Apidaecines & $\begin{array}{l}\text { GNNRPVY I PQPRPPHPR I } \\
\text { GN R R Y I POPRPPHPRL } \\
\text { GN NRPI Y I POPRPPHPR }\end{array}$ \\
\hline PR-39 & RRRPRPPYLPRPRPPPFFPPRLPPR I PPGFPPRFPPRFP NH 2 \\
\hline
\end{tabular}


biens [5] (Tableau I). La proxénopsine engendre, outre le XPF, la xénopsine qui est l'équivalent de la neurotensine des mammifères. La procaeruléine engendre le CPF et une hormone, la caeruléine, qui est le pendant de la gastrine/CCK des mammifères. Le XPF et le CPF sont des peptides de 25 à 27 acides aminés, riches en lysines et actifs à des doses micromolaires contre une grande variété de bactéries Gram ${ }^{+}$et $\mathrm{Gram}^{-}$et des champignons. Un autre précurseur d'hormone, la prolévitide, produit également un fragment de 25 acides aminés baptisé PGK dont la structure et les propriétés sont similaires à celles du XPF [5]. D'autres peptides antibactériens en hélice amphiphile de la peau du xénope, le PGLa [5] et les magainines [6], sont issus de précurseurs monofonctionnels (Tableau I). Les magainines I et II, ou PGS I et PGS II, sont deux peptides fortement homologues de 23 acides aminés provenant d'un précurseur commun qui contient cinq copies de magainine I et une copie de magainine II. Ces deux peptides, qui ne diffèrent que par deux substitutions en positions 10 et 22, ont un spectre d'activité antimicrobien très étendu (Tableau II). A des doses micromolaires, les magainines stoppent la croissance et/ou induisent la lyse osmotique de nombreuses souches bactériennes, $\mathrm{Gram}^{+}$et $\mathrm{Gram}^{-}$, de champignons et de protozoaires. Elles induisent une lyse irréversible de cellules tumorales hématopoḯtiques [7] et de tumeurs solides de diverses origines mais sont sans effet sur les cellules différenciées des eucaryotes.

La peau de nombreuses autres espèces d'amphibiens sécrète également des peptides antimicrobiens dont l'organisation structurale est voisine de celle des peptides du xénope. Citons en particulier les bombinines, peptides de 27 acides aminés isolés de la peau d'une grenouille européenne, Bombina varietaga [8]. Tous les membres de la famille des bombinines (Tableau I) ont des extrémités $\mathrm{N}$ terminales hypervariables et des extrémités C-terminales 14-27 identiques. Ces peptides ont une activité bactériostatique contre certains $\mathrm{Gram}^{+}$et Gram-. Le spectre d'activité semble étroit puisque, sur $\mathrm{m} / \mathrm{s} n^{\circ} 5$, vol. 8, mai 92

Tableau II

ACTIVITÉ ANTIMICROBIENNE DES PEPTIDES DE DÉFENSE DE LA PEAU DU XÉNOPE

\begin{tabular}{|c|c|c|c|c|c|}
\hline \multirow[t]{2}{*}{ Organisme } & \multicolumn{5}{|c|}{$\begin{array}{c}\text { Concentration minimale d'inhibition }{ }^{(a)} \\
\text { de la croissance }(\mu \mathrm{g} / \mathrm{ml})\end{array}$} \\
\hline & $\begin{array}{l}\text { Magai- } \\
\text { nine II }\end{array}$ & PGLa & XPF & CPF & PGQ \\
\hline $\begin{array}{l}\text { Escherichia coli } \\
\text { Klebsiella pneumoniae } \\
\text { Pseudomonas aeruginosa } \\
\text { Staphylococcus aureus } \\
\text { Streptococcus faecalis } \\
\text { Candida albicans }\end{array}$ & $\begin{array}{l}62-125 \\
125-250 \\
125-250 \\
500 \\
500 \\
250-500\end{array}$ & $\begin{array}{l}62-125 \\
250-500 \\
250-500 \\
500 \\
500 \\
250-500\end{array}$ & $\begin{array}{l}16-31 \\
62-125 \\
125-250 \\
250-500 \\
250-500 \\
250-500\end{array}$ & $\begin{array}{l}16-31 \\
31-62 \\
62-125 \\
16-31 \\
125-250 \\
125-250\end{array}$ & $\begin{array}{l}62-250 \\
125-250 \\
250-500 \\
250-500 \\
250-500 \\
250-500\end{array}$ \\
\hline \multicolumn{6}{|c|}{ Concentration lytique minimale ${ }^{(b)}(\mu \mathrm{g} / \mathrm{ml})$} \\
\hline $\begin{array}{l}\text { Paramecium caudatum } \\
\text { Tetrahymena pyriformis } \\
\text { Acanthamoeba castellani }\end{array}$ & $\begin{array}{l}10 \\
20 \\
2\end{array}$ & $\begin{array}{l}5 \\
20 \\
2\end{array}$ & $\begin{array}{l}10 \\
20 \\
2\end{array}$ & $\begin{array}{l}\mathrm{nd}^{(\mathrm{c})} \\
\text { nd } \\
\text { nd }\end{array}$ & $\begin{array}{l}\text { nd } \\
\text { nd } \\
\text { nd }\end{array}$ \\
\hline
\end{tabular}

(a) La concentration minimale de peptide produisant l'inhibition de la croissance bactérienne est déterminée par turbidimétrie à $600 \mathrm{~nm}$ en incubant 0,7 à $14 \times 10^{5}$ bactéries avec des concentrations croissantes du peptide à tester dans $1 \mathrm{ml}$ de milieu de croissance.

(b) La concentration minimale de peptide produisant la lyse des protozoaires est déterminée par observation directe au microscope optique des organismes 15 minutes après addition du peptide à tester

dans le milieu de culture
(c) nd: non déterminé.

plus de 200 souches testées, seuls Escherichia coli et Staphylococcus sont sensibles à la bombinine. Le motif $\mathrm{N}$ terminal 1-13 semble porter l'activité de la molécule car la bombinine14-27 de synthèse est inactive.

La dermaseptine est un peptide de 34 acides aminés (Tableau I) isolé de la peau d'une rainette arboricole, Phyllomedusa sauvagii [9]. Ce peptide fortement cationique peut adopter aussi une structure en hélice amphiphile qui recouvre la partie 1-27 de la molécule (figure 1). La dermaseptine a un spectre d'activité particulier puisqu'elle est sans action sur les bactéries mais provoque la lyse immédiate de certains champignons mycéliens et de protozoaires ciliés pathogènes chez l'homme. A des doses micromolaires, la dermaseptine est fongicide pour les Aspergillus, des champignons mycéliens pathogènes et ubiquitaires qui sont responsables d'infections opportunistes redoutables chez les patients immunodéprimés tels les grands brûlés, les transplantés, les sidéens ou les leucémiques. La dermaseptine induit également la lyse osmotique de la forme promastigote de la Leishmania (figure 2, p. 428), protozoaire cilié responsable d'infections muco- viscérales pour lesquelles aucun traitement satisfaisant n'existe à l'heure actuelle. La dermaseptine est, en revanche, sans effet sur les cellules eucaryotes.

La plupart des peptides antimicrobiens de la peau des amphibiens sont également présents dans le tractus gastro-intestinal. La muqueuse de l'estomac du xénope contient des cellules granulaires multinucléées dont la morphologie et l'ultrastructure sont comparables à celles des cellules glandulaires de la peau. Ces cellules multinucléées de la paroi stomacale synthétisent puis sécrètent dans la lumière de l'estomac par la voie holocrine toute la panoplie des peptides antimicrobiens présents dans la peau de l'animal. Outre les magainines, le XPF, le PGLa et le CPF, ces cellules co-produisent un peptide antimicrobien additionnel de 24 acides aminés, le PGQ (Tableau I), que l'on a par la suite trouvé également dans la peau [10]. L'activité du PGQ est comparable à celle des magainines.

\section{Des peptides antimicrobiens à ponts disulfure formant des feuillets $\beta$ : les défensines}

Les cellules phagocytaires sont l'un des composants majeurs de la défense 

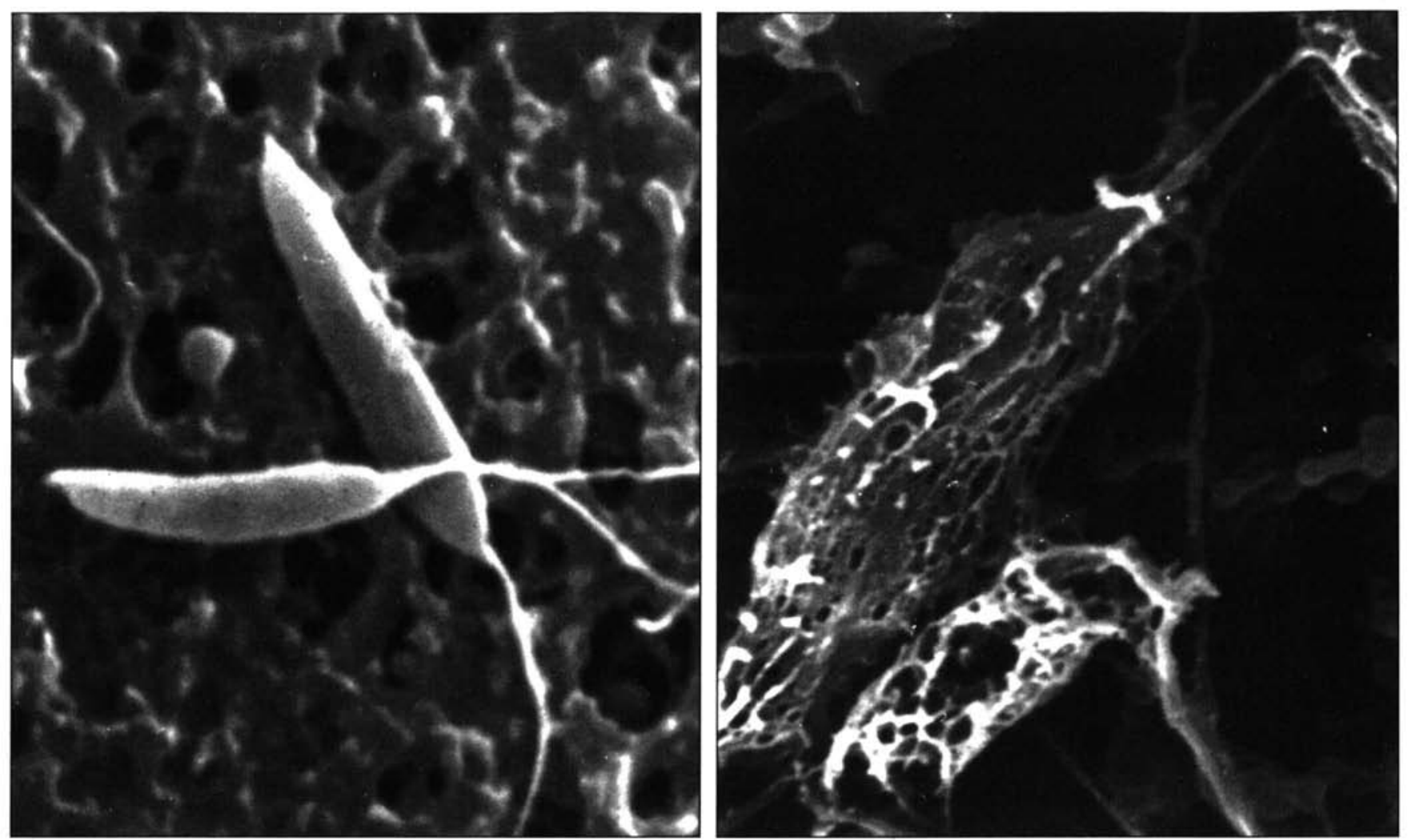

Figure 2. Activité lytique de la dermaseptine sur la forme promastigote de la Leishmania mexicana observée au microscope à balayage. Dès les minutes qui suivent l'addition du peptide au milieu de culture, la membrane du protozoaire est constellée de perforations (cliché de gauche). La rupture de la structure membranaire en de multiples points a entraîné la mort du micro-organisme. Le cliché de droite montre le parasite non traité par la dermaseptine.

non spécifique contre les microorganismes que l'on trouve tout au long de la phylogenèse des invertébrés et des vertébrés. Parmi les cellules phagocytaires circulantes, les neutrophiles polynucléaires jouent un rôle primordial en englobant puis en digérant, par des mécanismes dépendant ou non de l'oxygène, toute une variété de micro-organismes. C'est dans la digestion indépendante de l'oxygène qu'intervient, outre une batterie d'hydrolases comme la cathepsine $G$ et le lysozyme, une panoplie de petits peptides cationiques doués d'activité membranolytique, les défensines [11]. Ces peptides lytiques sont mis en présence de leurs cibles lors de la fusion des lysosomes du neutrophile où ils sont stockés, avec les phagosomes qui contiennent les micro-organismes ingérés. Chez les mammifères, les peptides de la famille des défensines sont les principaux peptides antimicrobiens synthétisés par les neutrophiles du contenu des granules azurophiles. Quinze peptides appartenant à cette famille ont été isolés et caractérisés dans plusieurs espèces de mammifères, y compris l'homme. Tous ces peptides sont constiutés de 30 à 34 acides aminés (Tableau I). Ils ont un caractère cationique marqué dû à leur richesse en arginine et possèdent tous six résidus de cystéine arrangés en trois ponts disulfure. Chez l'homme, les défensines HNP-1, HNP-2 et HNP-3 sont présentes en quantité équimoléculaire dans les neutrophiles. Les défensines sont synthétisées via des précurseurs de structure très voisine. Les préprodéfensines comprennent un peptide signal hydrophobe de 19 acides aminés et un fragment anionique de 40-45 acides aminés qui précède la séquence progénitrice de la défensine. La plupart des défensines sont cytotoxiques envers les cellules eucaryotes, et le fragment anionique masque, dans le précurseur, l'activité lytique de la défensine jusqu'à sa séquestra- tion dans le lysosome. Les défensines ont une activité membranolytique sur une grande variété de microorganismes. Elles tuent les bactéries Gram + et Gram -, de nombreux champignons ainsi que certains virus à enveloppe tel l'Herpes simplex. Des doses nanomolaires de l'HNP-1 ont un effet chimioattracteur pour les monocytes humains. Il est vraisemblable que la libération de cette défensine à proximité d'un site d'infection ou d'inflammation facilite l'accumulation locale des monocytes. L'examen par RMN de la structure des défensines en solution indique que ces peptides se replient en feuillets $\beta$-amphiphiles [11]. Les défensines sont susceptibles d'interagir avec les bicouches lipidiques, naturelles ou artificielles, pour y constituer des canaux ioniques dépendant du voltage qui perméabilisent la membrane et provoquent la lyse cellulaire.

Bien que les défensines soient synthétisées et utilisées par les neutrophiles circulants, ces peptides sont égale- 
ment produits par d'autres cellules myéloïdes, en particulier les macrophages pulmonaires, mais aussi par des cellules non myéloïdes. Ainsi la cryptidine (Tableau I), défensine de la souris, est synthétisée dans des cellules non myéloïdes de l'épithélium du petit intestin, les cellules de Paneth [12]. Le peptide antimicrobien de la trachée, ou TAP, défensine de 38 acides aminés (Tableau I), est synthétisé et excrété par des cellules spécialisées de la muqueuse respiratoire du bœuf où il participe à la lutte contre les micro-organismes telluriques [13]. Les défensines ne sont pas restreintes au phylum des vertébrés puisque des peptides - phormicines, sapécines, royalisines - dont la structure est fortement apparentée à celle des défensines de mammiferes (Tableau I) sont présents dans l'hémolymphe de certains insectes [14]. Ces peptides, outre leur rôle antimicrobien, pourraient avoir un rôle de facteur de croissance durant l'ontogenèse. Enfin, dans le règne végétal, des peptides du type défensine, les thionines (Tableau I), sont synthétisés dans les feuilles des mono- et dicotylédones [15] lors d'infections bactérienne ou fongique.

\section{Les peptides antimicrobiens riches en proline}

Outre les défensines, les neutrophiles des mammifères synthétisent en abondance une série de peptides antimicrobiens, de petite taille et fortement cationiques, les bacténécines [16]. Ces peptides, composés de 42 à 59 acides aminés (Tableau I), ont une composition en acides aminés et une séquence primaire peu communes. La proline et l'arginine représentent respectivement plus de $45 \%$ et $23 \%$ des acides aminés constitutifs. Les autres acides aminés sont apolaires, Ile et Leu étant fortement majoritaires. La séquence primaire de ces peptides est constituée par la répétition des motifs Pro-ArgPro ou Arg-Pro-Pro, séparés par un acide aminé hydrophobe. Les bacténécines sont actives principalement contre les bactéries et certains virus. Elles tuent Salmonella typhimurium, Klebsiella pneumoniae et Escherichia coli et stoppent la croissance d'Enterobacter cloacae et de Pseudomonas aeruginosa. Les bacténécines perméabilisent les membranes $\mathrm{m} / \mathrm{s} n^{\circ} 5$, vol. 8, mai 92 externes et internes et bloquent la chaîne respiratoire des bactéries. La structure secondo-tertiaire des bacténécines est bien évidemment différente de celle des autres peptides antimicrobiens. La présence de nombreux résidus proline structure le peptide en une série de coudes qui alternent avec des motifs peu structurés et plus flexibles. Néanmoins, l'analyse par graphisme moléculaire et minimisation énergétique de ces structures montre qu'elles présentent des surfaces polaires et des surfaces apolaires topologiquement distinctes.

A l'instar des défensines, les bacténécines sont également produites dans des cellules non myéloïdes et chez les invertébrés. Un peptide de 39 acides aminés, baptisé PR-39, montre (Tableau I) des analogies structurales remarquables avec les bacténécines des neutrophiles bien qu'il soit synthétisé par les cellules de la muqueuse intestinale chez le porc [17]. Les apidaecines d'insectes - peptides antibactériens riches en proline - sont les représentants des bacténécines chez les invertébrés (Tableau I).

\section{Un mécanisme d'action commun ?}

Très divers dans leur structure primaire, leur taille et leur spécificité d'action, les peptides antimicrobiens des vertébrés, comme ceux des invertébrés, ont tous des propriétés membranolytiques marquées vis-à-vis de leurs cibles. Tous également sont fortement cationiques et présentent un caractère amphiphile marqué qui se révèle lors de l'examen de leur structure tridimensionnelle. Que ces peptides adoptent des structures en hélice $\alpha$ ou en feuillets $\beta$, ou constituent des coudes qui alternent avec des parties plus flexibles, tous s'organisent de façon que les acides aminés polaires ou chargés soient topologiquement séparés des acides aminés apolaires. L'action lytique de ces peptides ne semble pas relayée par des récepteurs ou des enzymes spécifiques portés par la membrane, interne ou externe, des micro-organismes. En effet, la magainine II ou la cécropine A synthétiques dans lesquelles tous les acides aminés ont la configuration D sont aussi actives que leurs parents naturels, bien qu'elles forment en solution des héli- ces gauches. C'est donc dans l'amphipatie des structures qu'il faut rechercher l'explication des mécanismes moléculaires qui aboutissent à la lyse cellulaire.

Toute une série de faits expérimentaux, la plupart obtenus sur les peptides antimicrobiens en hélice $\alpha$, ont conduit à l'hypothèse selon laquelle ces peptides exerceraient leurs effets via la formation de canaux ioniques dans les bicouches lipidiques. En particulier, les peptides antimicrobiens se lient avec une affinité élevée et une stoechiométrie finie à la face externe des liposomes lorsque ceux-ci sont constitués de phospholipides acides comme la phosphatidylsérine ou le phosphatidylglycérol. Cette liaison est abolie si ces lipides sont remplacés par des lipides zwittérioniques* [18]. La neutralisation des charges positives portées par les lysines de la cécropine ou de la magainine provoque la disparition de l'activité lytique alors que cellc-ci augmente si l'on utilise des analogues exhibant un degré d'hélicité supérieur à celui des peptides natifs. Enfin, la liaison des peptides antimicrobiens aux membranes provoque une dissipation du potentiel membranaire en quelques minutes, l'intensité de cette dissipation étant par ailleurs corrélée à l'activité lytique du peptide. L'annulation artificielle du potentiel de membrane de la cellule cible rend la cellule réfractaire à l'action lytique des peptides antibactériens [19]. Le modèle qui prévaut à l'heure actuelle pour rendre compte de ces observations stipule que les interactions électrostatiques entre les résidus basiques du peptide et les têtes négatives des phospholipides de la membrane neutralisent le caractère cationique du peptide et favorisent, dans un premier temps, sa stabilisation en hélice $\alpha$ amphiphile dont le grand axe s'oriente parallèlement à la surface membranaire (figure 3, p. 430). Dans un deuxième temps, l'existence d'une différence de potentiel membranaire, donc d'un champ électrostatique, et du moment dipolaire permanent du peptide orienté selon le grand axe de l'hélice favorisent l'insertion tête la première du peptide dans la membrane de telle façon que le moment

* Lipides dont la charge nette est nulle au pH physiologique. 


\section{RÉFÉRENCES}

9. Mor A, Nguyen VH, Delfour A, Migliore-Samour D, Nicolas P. Isolation, aminoacid sequence and synthesis of dermaseptin, a novel antimicrobial peptide of amphibian skin. Biochemistry 1991; 30 . 8824-30.

10. Moore KS, Bevins CL, Brasseur MM, et al. Antimicrobial peptides in the stomach of Xenopus laevis. J Biol Chem 1991; 266 : 19851-7.

11. Lehrer RI, Ganz T, Selsted E. Defensins : endogenous antibiotic peptides of animal cells. Cell $1991 ; 64: 229-30$

12. Ouelette AJ, Greco RM, James M, Frederick D, Naftilan J, Fallon JT. Developmental regulation of cryptdin, a corticostatin/defensin precursor mRNA in mouse small intestinal crypt epithelium. J Cell Biol $1989 ; 108$ : 1687-95.

13. Diamond G, Zasloff M, Eck H, Brasseur M, Maloy WL, Bevins CL. Tracheal antimicrobial peptide, a cysteine-rich peptide from mammalian tracheal mucosa. Proc Natl Acad Sa USA 1991; 88 : 3952-6.

14. Fujiwara S, Imai J, Fujiwara M, Yaeshima T, Kawashima T, Kobayashi K. A potent antibacterial protein in royal jelly. $J$ Biol Chem 1990 ; 265 : 11333-7.

15. Bohlmann H, Clausen S, Behnke S, et al. Leaf-specific thionins of barley : a novel class of cell wall protein toxic to plantpathogenic fungi and possibly involved in the defence mechanism of plants. EMBO J $1988 ; 7: 1559-65$.

16. Frank RW, Gennaro R, Schneider K, Przybylski M, Romeo D. Aminoacid sequence of 2 proline rich bactenecins. J Biol Chem $1990 ; 265: 18871-4$

17. Agerberth B, Lee JY, Bergman T, et al. Aminoacid sequence of PR-39. Isolation from pig intestine of a new member of the family of proline-arginine rich antibacterial peptides. Eur J Biochem 1991 ; 202 : 849-54.

18. Rana FR, Macias EA, Sultany CM, Modzrakowski ML, Blazk J. Interaction between magainin 2 and Salmonella typhimurium outer membranes : effect of lipopolysaccharide structure. Biochemistry 1991; 30 : 5858-66.

19. Cruciani RA, Barker JL, Zasloff $M$, Chen HC, Colamonici O. Antibiotic magainins exert cytolytic activity against tranformed cell lines through channel formation.

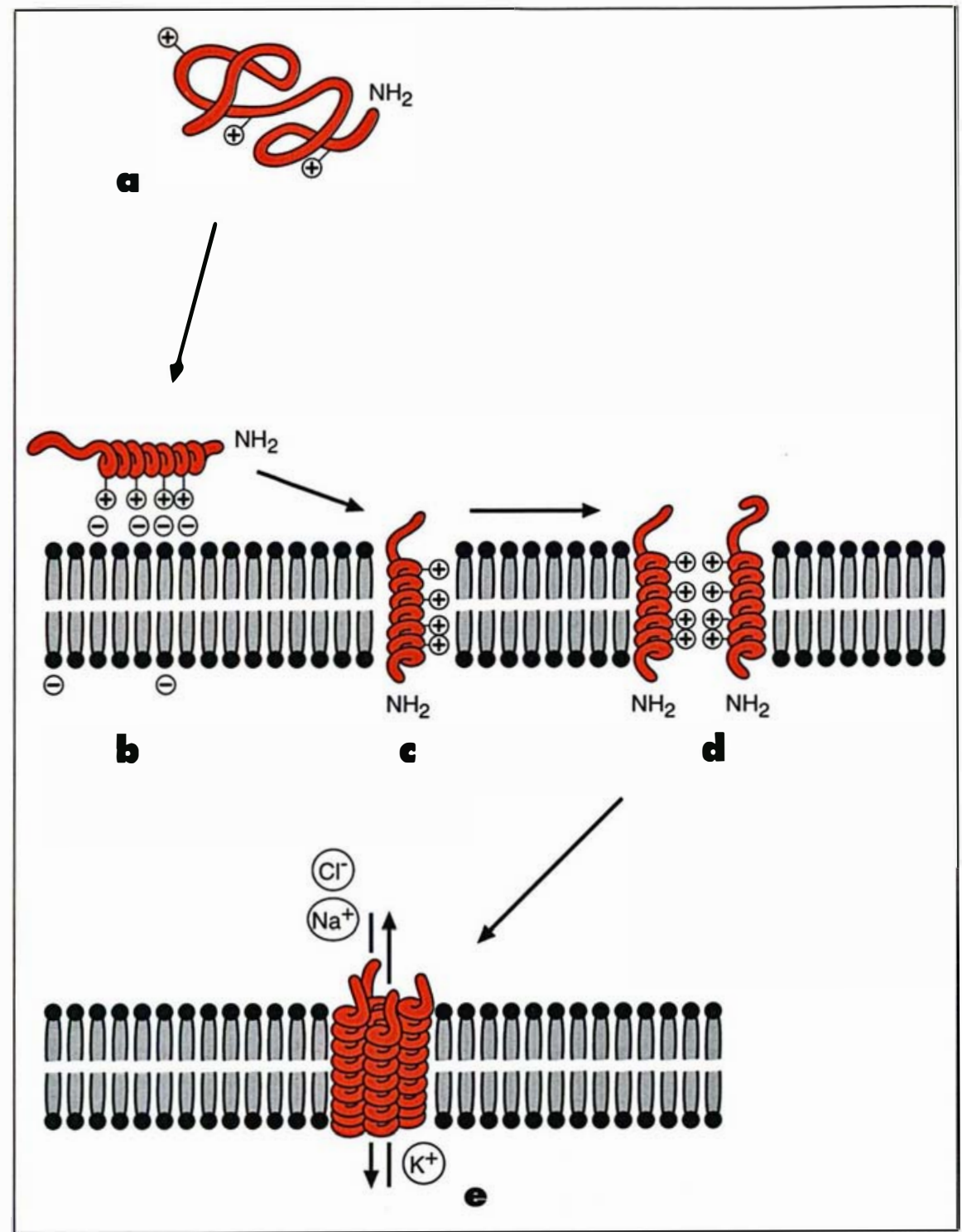

Figure 3. Un modèle probable de l'action membranolytique des peptides antimicrobiens en hélice amphipatique. Le peptide, qui est peu structuré en solution aqueuse (a), peut interagir avec la membrane plasmique par le biais d'interactions électrostatiques entre les chaînes latérales chargées positivement de ses résidus de lysine et les têtes négativement chargées de certains phospholipides membranaires (b). Le peptide adopte alors au contact de la membrane une structure en hélice $\alpha$-amphipatique dont l'une des faces contient la majorité des résidus polaires et chargés, et l'autre face, les résidus apolaires. L'organisation de la chaîne peptidique en hélice provoque également l'apparition d'un dipôle permanent orienté le long du grand axe, d'intensité équivalente à l'existence d'une demi-charge positive en $\mathrm{N}$-terminal et d'une demi-charge négative en $\mathrm{C}$-terminal. Dans le cas d'une cellule vivante au repos (c), la membrane est chargée électriquement et présente un excès de charges positives sur sa face cytoplasmique. L'interaction électrostatique entre ce champ électrique membranaire et le dipôle peptidique favorise l'insertion orientée du peptide dans la membrane. Les peptides insérés diffusent latéralement dans la bicouche lipidique et s'agrègent (d) de façon que leurs faces apolaires interagissent avec les chaînes hydrocarbonées des lipides. L'assemblage de quatre à six monomères forme un pore ionique (e) dont le canal central est constitué par les faces polaires et chargées des hélices transmembranaires. Ce pore ionique laisse passer les cations et les anions avec toutefois une légère spécificité anionique. Si ces pores sont en quantité assez élevée, l'écoulement des ions dans le sens de leur gradient de concentration provoque la dissipation du potentiel transmembranaire et la mort de la cellule. 
dipolaire et le champ électrostatique soient antiparallèles. Ce moment dipolaire associé à l'hélice provient de la somme vectorielle des moments microscopiques associés aux liaisons hydrogènes $\mathrm{N}-\mathrm{H}-\mathrm{O}=\mathrm{C}-\mathrm{H}$ et est indépendant des charges additionnelles portées par les chaînes latérales des résidus chargés. Pour une hélice de 20 résidus, l'intensité de ce moment est de $63 \mathrm{D}^{*}$ et est équivalente à l'existence d'une demi-charge positive en $\mathrm{N}$-terminal et d'une demicharge négative en $\mathrm{C}$-terminal. Les peptides insérés dans la membrane s'agrègent pour former des canaux transmembranaires constitués de quatre à six monomères. Dans ces canaux, les hélices sont orientées parallèlement les unes aux autres de manière que leur face apolaire soit tournée vers l'extérieur du pore central et interagisse avec les chaînes hydrocarbonées des lipides. Les faces polaires des hélices, tournées vers l'intérieur du canal, bordent le pore central. De nombreuses investigations électrophysiologiques ont montré que ces canaux voltagedépendants laissaient passer les cations $\mathrm{Na}^{+}$et $\mathrm{K}^{+}$et les anions $\mathrm{Cl}^{-}$ avec toutefois une très légère spécificité anionique. La perturbation des équilibres ioniques engendrée par ces canaux entraînerait la dissipation rapide du potentiel membranaire et la lyse cellulaire. Le rôle que joue le potentiel de membrane pour l'insertion initiale du peptide permet de comprendre la dépendance de ces canaux visà-vis du voltage alors que les microvariations de potentiel et la faible durée de vie de ces agrégats rendraient compte des brèves durées d'ouverture, de l'ordre de $100 \mathrm{~ms}$, de ces canaux. Si ce modèle, bien qu'encore discuté, rend bien compte des effets lytiques, il n'explique en rien la remarquable spécificité d'action des peptides antimicrobiens. Il est vraisemblable que les bases de cette spécificité soient à rechercher pour une part dans la composition lipidique et lipopolysaccharidique des membranes cibles, mais également dans la nature des chaînes latérales des acides aminés apolaires du peptide qui sont susceptibles d'établir des interactions hydrophobes avec les lipides constitutifs de la membrane.

\footnotetext{
- L'unité D est le Debye.
}

$\mathrm{m} / \mathrm{s} n^{\circ} 5$, vol. 8, mai 92

\section{Les peptides du système de défense chimique : des effecteurs ancestraux de l'immunité conservés lors de l'évolution}

Les peptides antimicrobiens, que l'on croyait être l'apanage des microorganismes, sont largement distribués dans la nature, dans l'ensemble du règne animal et du règne végétal. Présents sur la peau et les parois des muqueuses respiratoires et intestinales des vertébrés, ces peptides trouvent pour la plupart des correspondants de structure identique ou voisine chez les invertébrés.

La présence de peptides antibactériens chez les vertébrés, peptides que l'on peut considérer comme des effecteurs ancestraux de l'immunité, a plus qu'une signification vestigiale. Ce n'est pas surprenant si l'on considère les avantages que peut apporter le système de défense chimique chez les vertébrés pour aider le système immunitaire classique, voire le suppléer en cas de déf aillance. En effet, un répertoire fixe, mais étendu, de petits peptides antimicrobiens offre aux animaux supérieurs un mode de contrôle particulièrement efficace des micro-organismes de leur flore naturelle. Si l'on considère, en effet, qu'une bactérie se multiplie environ 50 fois plus vite qu'une cellule $B$ productrice d'immunoglobuline, qu'un précurseur de peptide antimicrobien est synthétisé 100 fois plus vite qu'une IgM, que les peptides antimicrobiens sont induits par des signaux simples et diffusent beaucoup plus vite qu'un anticorps, on se rend compte que ces peptides à coût faible et à spectre d'action étendu permettent une réponse défensive dont la vitesse est très supérieure à la vitesse de multiplication des micro-organismes. Ils sont donc parfaitement adéquats pour offrir une première ligne de défense efficace contre les agents infectieux et assurer également un contrôle en continu de la prolifération des micro-organismes commensaux. Ce système de défense chimique offre, de plus, une possibilité de secours partiel en cas de défaillance momentanée ou prolongée du système immunitaire classique telle celle observée chez les patients immunodéprimés

\section{Summary}

Antimicrobial peptides in vertebrates : a chemical defense system

Vertebrates must defend themselves against host invasion of occasional and obligate pathogens as well as against uncontrolled proliferation of commensal micro-organisms. In addition to the highly specific cellmediated immune system, vertebrate animals are endowed for that purpose with an additional chemical defense system involving antimicrobial peptides analogous to those found in invertebrates. These peptides are produced by lymphoïd tissues as well as by non-lymphoid cells of the mucous epithelia of the respiratory system, the intestinal system and the skin and cause cell lysis and death of a broad array of micro-organisms including bacteria, fungi and protozoa. Most of the antimicrobial peptides so far isolated from vertebrates are small-sized and positively charged and fall into 3 distinct groups: peptides with amphiphatic $\alpha$ helix structure, disulfide bridged peptides with amphiphatic $\beta$-sheet structure and proline-rich peptides. Whereas the precise mechanism of action of these peptides remains to be defined, their microbicidal effects are very likely due to their capacity to form ion channels which span the microbial membrane and permabilize the cell. This cell-free defense system provides vertebrates with small-sized peptides that are promptly synthesized upon induction, easily stored in large amounts and readily available for antimicrobial warfare.

\section{TIRÉS A PART}

\section{P. Nicolas.}

Erratum : $m / s n^{\circ} 4$, vol. 8, avril 1992. Dans l'article : Structure et fonction du complexe CD16: $\zeta: \gamma$ des cellules NK (Nathalie Rochet, et al.), page 364, 1 re colonne, ligne $30 \mathrm{du} 2 \mathrm{e}$ paragraphe, il faut lire chromosome 1 et non chromosome 11 . 